\title{
ALEJANDRO O'REILLY Y EL INGENIERO BELTRÁN BEAUMONT EN SANTIAGO DE CUBA: CAUSAS Y PRINCIPIOS DE UN PROYECTO DE FORTIFICACIÓN FRUSTRADO (1764-1766)
}

\section{ALEJANDRO O'REILLY AND THE ENGINEER BELTRÁN BEAUMONT IN SANTIAGO DE CUBA: CAUSES AND PRINCIPLES OF AN UNSUCCESSFUL FORTIFICATION PROJECT (1764-1766)}

\section{Ignacio J. López Hernández ${ }^{1}$ Universidad de Almería}

\section{Resumen:}

El final de la guerra de los Siete Años tuvo un impacto decisivo en la configuración defensiva de la América española del último tercio del siglo XVIII. En este contexto, este trabajo pretende definir de qué modo se introdujo este nuevo paradigma de la fortificación en el caso de Santiago de Cuba a partir de la documentación de un proyecto inédito del ingeniero Beltrán Beaumont y del mariscal de campo Alejandro O'Reilly. Su análisis permitirá concretar las causas de su fracaso en factores tanto personales como técnicos y estratégicos.

Palabras clave: Alejandro O'Reilly, Fortificación, Santiago de Cuba.

\section{Abstract:}

The end of the Seven Years' War had a decisive impact on the defensive configuration of the Spanish American territories in the following years. This article aims to identify how Santiago de Cuba was involved in this new strategy by documenting an unknown fortification project by the engineer Beltrán Beaumont and the Marshal Alejandro O'Reilly. Its analysis will allow us to recognise a both personal and technical conflict as the cause of its unsuccessful implementation.

Keywords: Alejandro O'Reilly, Fortification, Santiago de Cuba.

Fecha de recepción: 01/10/2020

Fecha de aceptación: 22/02/2021

\footnotetext{
${ }^{1}$ El presente artículo se integra dentro de los resultados del proyecto de investigación "Arquitecturas del Poder en el Caribe y el Sudeste Asiático. 1729-1764" (PGC2018-099323-B-I00) financiado por el Ministerio de Ciencia e Innovación.
} 


\section{AMERICANISTAS}

ISSN 1988-7868
Ignacio J. López Hernández

Alejandro O'Reilly y el ingeniero Beltrán Beaumont en Santiago de Cuba: causas y principios de un proyecto de fortificación frustrado (1764-1766).

\section{Introducción}

El estudio de la historia de la ingeniería y de los ingenieros en la América hispana goza en la actualidad de plena vigencia. La historiografía americanista ha vuelto a incorporar en los últimos años numerosos trabajos que, sustentados por equipos y proyectos de investigación multidisciplinares, toman el testigo de autores de referencia como Angulo, Marco Dorta, Calderón Quijano o Zapatero. ${ }^{2}$ A pesar del camino recorrido, la disciplina aún precisa de estudios que definan plenamente el origen del sistema defensivo americano, así como su complejo proceso de configuración como elemento orgánico y mutable resultante de la aplicación de diferentes condicionantes técnicos, científicos, tácticos y, sobre todo, geoestratégicos. Como consecuencia, la fortificación en América y, más particularmente, la de su área del Caribe y golfo mexicano no puede ser entendida únicamente bajo el tradicional estudio de su patrimonio arquitectónico conservado. Así, resulta útil comprender las prioridades de cada época y territorio a través de los numerosos proyectos que quedaron en el papel, en los que se puede sondear un interesante debate entre ingenieros y gobernantes. A través del estudio comparado de planos y memorias de distintos protagonistas y épocas es posible advertir la evolución del concepto de fortificación a lo largo de las campañas militares que tuvieron desarrollo en el teatro bélico del Caribe. Asimismo, esto permite observar cómo la defensa de aquel territorio tuvo rasgos específicos y diferenciados de los europeos. Así, ya Zapatero postuló la existencia de una "escuela de fortificación hispanoamericana" en atención al modo diverso en que se implementaron aquí los esquemas y sistemas defensivos abaluartados. ${ }^{3}$ No obstante, esta afirmación, hoy generalizada, quedó entonces huérfana de un estudio más profundo que definiera sus características y fases de configuración. Para sostener o rebatir tal posicionamiento es necesario acotar prácticas determinadas para desde ahí proyectar rasgos comunes y particulares, que no solo independicen la

\footnotetext{
${ }^{2}$ Diego Angulo Íñiguez, Bautista Antonelli. Las fortificaciones americanas del siglo XVI. Madrid: Hauser y Menet, 1952; Enrique Marco Dorta, Cartagena de Indias: puerto y plaza fuerte. Cartagena de Indias: Alfonso Amadó, 1960; José Antonio Calderón Quijano, Las Fortificaciones españolas en América y Filipinas. Madrid: Mapfre, 1996; Juan Manuel Zapatero, La fortificación abaluartada en América. San Juan de Puerto Rico: Instituto de la Cultura Puertorriqueña, 1978.

3 Juan Manuel Zapatero, Historia del Castillo San Lorenzo el Real de Chagre. Madrid: Ministerio de Defensa, Servicio Histórico Militar, 1985, p. 145; Juan Manuel Zapatero, La Guerra del Caribe en el siglo XVIII. Madrid: Servicio Histórico Militar y Museo del Ejército, 1990, pp. 97-120.
} 


\section{AMERICANISTAS}

Ignacio J. López Hernández

Alejandro O'Reilly y el ingeniero Beltrán Beaumont en Santiago de Cuba: causas y principios de un proyecto de fortificación frustrado (1764-1766).

\section{ISSN 1988-7868}

fortificación hispanoamericana de los referentes metropolitanos sino también de la desarrollada por otras potencias competidoras. ${ }^{4}$

Este último enfoque resulta especialmente esclarecedor al analizar la defensa de espacios concretos en los que se enfrentaron intereses franceses, españoles y británicos. Uno de ellos estuvo definido en el triángulo que conforman el oriente de Cuba, la colonia francesa de Saint-Domingue y Jamaica. ${ }^{5}$ Esta región del Caribe ostentó un alto valor estratégico por controlar la navegación a través del Paso de los Vientos, flanqueado por costas con bahías de gran calidad. Su defensa por tanto resultó capital para las distintas Coronas que se enfrentaron a la fortificación de manera dispar. Ya tuve la oportunidad de abordar una parte de este problema en el contexto concreto de Santiago de Cuba durante la Guerra del Asiento, en donde se implementó con éxito el plan de defensa y fortificación que repelió el ataque del vicealmirante Edward Vernon. ${ }^{6}$ Entonces, se analizó cómo el ingeniero Francisco de Langle planteó la defensa de la jurisdicción santiaguera como una terea con implicaciones y condicionantes diversos a los que la tradición de la poliorcética europea prevenía. Así, por ejemplo, se advirtió cómo la fortificación de campaña tuvo gran protagonismo, resultando una herramienta eficaz y adaptada a un tipo de guerra que aún no incorporaba las complejas técnicas de asedio europeas y que se veía completamente dominada por agentes como el clima o las enfermedades.

No obstante, estas conclusiones se acomodan específicamente a las peculiaridades de aquella campaña, que son diversas de las que se plantearon a partir de la guerra de los Siete Años. Por entonces, los británicos supieron sobreponerse a los errores de 1741 incorporando nuevas tácticas para las que las fortificaciones del Caribe hispano no estaban adaptadas. El consecuente directo más célebre fue la toma de La Habana en 1762

\footnotetext{
${ }^{4}$ Este tema ha sido abordado en distintos proyectos liderados por los Dres. Alfredo J. Morales y Pedro Luendo, de los que he formado parte y que han cristalizado en la monografía Pedro Cruz Freire, Manuel Gámez Casado, Ignacio J. López Hernández, Pedro Luengo, Alfredo J. Morales, Estrategia y Propaganda. Arquitectura militar en el Caribe (1689-1748). Roma: L'Erma di Bretschneider, 2020.

${ }^{5}$ Véase Alfredo J. Morales, "Cuba y Jamaica. Conflictos en el Caribe", en Pedro Cruz Freire e Ignacio J. López Hernández (coords.), Ingeniería e Ingenieros en la América Hispana. Siglos XVIII y XIX. Sevilla Editorial Universidad de Sevilla, 2017, pp. 13-28.

${ }^{6}$ Ignacio J. López Hernández, "La defensa de Santiago de Cuba al ataque de Vernon de 1741: Principios de fortificación para la Guerra en el Caribe", Anuario de Estudios Americanos, Vol. 76, $\mathrm{n}^{\circ} 1$ (Sevilla, 2019), pp. 177-207.
} 

causas y principios de un proyecto de fortificación frustrado (1764-1766).

\section{ISSN 1988-7868}

tras la rendición del castillo del Morro y el bombardeo de la ciudad desde las indefensas alturas de la Cabaña. Como resultado, tras el Tratado de París de 1763 se asiste a un despliegue de medios sin precedentes para la actualización tecnológica y tipológica del sistema defensivo de las principales plazas americanas, ${ }^{7}$ de las que el caso habanero es paradigmático. ${ }^{8}$ Este proceso ha sido bien estudiado en la mayoría de sus ejemplos, si bien aún quedan pendientes trabajos que acoten la repercusión de esta tendencia en puertos considerados a priori secundarios como el de Santiago de Cuba. ${ }^{9}$ Así, este artículo aspira a definir cuáles fueron las implicaciones de esta nueva política defensiva en esta plaza a partir de la documentación de un proyecto de fortificación inédito formulado por el ingeniero Beltrán Beaumont y el mariscal de campo Alejandro O'Reilly. Ello permitirá además documentar la tensa relación entre oficiales que siguió a la formación y aprobación de este proyecto, en donde intervinieron tanto factores personales como estratégicos.

\footnotetext{
${ }^{7}$ Alfredo J. Morales, "América y los ingenieros de Carlos III", en Esther Almarcha, Palma Martínez-Burgos y Elena Sainz (eds.), El Greco en su IV Centenario: Patrimonio hispánico y diálogo intercultural. Toledo: Universidad de Castilla la Mancha, 2016, pp. 67-78; Nelly Arcos Martínez, "Territorio y fortificación del Caribe: Agustín Crame, visitador de plazas 1777-1779" [en línea]. Biblio 3W. Revista Bibliográfica de Geografía y Ciencias Sociales, Vol. XXI, $\mathrm{n}^{\circ} 1152$ (2016). Universidad de Barcelona (Eds.). http://www.ub.es/geocrit/b3w-1152.pdf [Consulta: 18 septiembre 2019]. ISSN: 1138-9796.

${ }_{8}^{8}$ Pedro Luengo, "Military Engineering in Eighteenth-Century Havana and Manila: The Experience of the Seven Years War", War in History, Vol. 24, nº 1, (Great Easton, 2017), pp. 4-27.

${ }^{9}$ A pesar de las lagunas que aún persisten, se puede considerar que la historia defensiva de la ciudad de Santiago de Cuba y su jurisdicción goza de buena salud. A ella se le han dedicado recientemente dos tesis doctorales. La de Zaldívar Morales ha permitido definir el estado actual de las fortificaciones de Santiago desde el punto de vista de la gestión y conservación del conjunto monumental. Elsy Yamina Zaldívar Morales, La arquitectura de las construcciones militares históricas de Santiago de Cuba: recuperación, restauración y gestión patrimonial. Tesis doctoral inédita. Universidad de Alcalá, 2016; Por su parte, el trabajo de Padrón Reyes ha permitido entender cómo se integraron milicias indígenas en el sistema defensivo del sudeste cubano del siglo XVIII. Lilyam Padrón Reyes, Para que estén a punto con sus armas para lo que se ofreciere". Indios en la defensa del suroriente cubano, siglos XVI-XVIII. Santa Marta: UniMagdalena, 2021. Estos resultados se unen a los de la bibliografía precedente formada por las contribuciones de Francisco Castillo Meléndez, La defensa de la isla de Cuba en la segunda mitad del siglo XVII. Sevilla: Diputación Provincial, 1986, pp. 359-409; Omar López Rodríguez, El Castillo del Morro de Santiago de Cuba. La Habana: Editorial Pablo de la Torriente, 1997; Tamara Blanes Martín, "Historia y singularidad de una fortaleza, el Morro de Santiago de Cuba", Arquitectura Cuba, $\mathrm{n}^{\circ} 377$ (La Habana, 1998), pp. 32-36; Omar López Rodríguez, El Castillo del Morro: San Pedro de la Roca de Santiago de Cuba. Una pieza excepcional del Caribe Fortificado. Santiago de Cuba: Asociación Amigos del Castillo de Montjuic, Ministerio de Defensa de España y Oficina del Conservador de la Ciudad de Santiago de Cuba, 2017, pp. 31-45.
} 


\section{AMERICANISTAS}

Ignacio J. López Hernández

Alejandro O'Reilly y el ingeniero Beltrán Beaumont en Santiago de Cuba: causas y principios de un proyecto de fortificación frustrado (1764-1766).

\section{ISSN 1988-7868}

\section{Antecedentes: las fortificaciones de Santiago de Cuba hasta 1762}

El emplazamiento escogido para la fundación de la villa de Santiago de Cuba ya respondía principalmente a intereses de índole defensiva. Radicada al fondo de una profunda bahía de bolsa, la estrechez de su bocana permitía su fácil defensa, anticipándose así a las disposiciones que los primeros tratadistas españoles dictaron sobre este particular. ${ }^{10}$ Similares ventajas pesaron para la definitiva fundación de La Habana en la bahía de Carenas, erigiéndose poco a poco como cabecera de la isla por su estratégico posicionamiento para el encuentro de las naves de la Carrera de Indias antes de su tornaviaje por el Canal Nuevo de Bahamas. Así pues, mientras La Habana fue objeto de importantes planes y campañas de fortificación, la antigua capital de Santiago se vio relegada a un segundo plano. ${ }^{11}$ Solo la voluntad del gobernador Pedro de la Roca permitió dar inicio a la construcción de la primera fortificación de entidad de la bahía. ${ }^{12}$ Diseñado en 1637 por el ingeniero Juan Bautista Antonelli y concluido dos años más tarde, el castillo de San Pedro de la Roca custodiaba el acceso a la bahía desde las alturas de un monte escarpado. ${ }^{13} \mathrm{Su}$ emplazamiento brindaba una clara ventaja sobre las embarcaciones que tentaran cruzar la boca del puerto, si bien su extremada altura imposibilitaba tiros de artillería precisos sobre ellas. La solución pasaba por aprovechar el vértice escalonado y rocoso de la montaña para abrir plataformas de artillería. La primera de ellas, llamada de la Punta, se construiría al pie de la montaña en torno a $1651,{ }^{14}$ si bien sería perfeccionada por el ingeniero militar Juan de Císcara entre 1664 y 1668 , con ocasión de la necesaria reconstrucción del castillo tras la toma de la ciudad por parte del inglés Christopher Myngs. ${ }^{15}$ Entonces, Císcara completó el sistema defensivo de la

\footnotetext{
${ }^{10}$ Cristóbal de Rojas, Teorica y practica de fortificacion, conforme las medidas y defensas destos tiempos. Madrid: Luis Sanchez, 1598, fol. 3r-4v.

${ }^{11}$ Castillo Meléndez, op. cit., pp. 362-364.

${ }^{12}$ Lilyam Padrón Reyes, "Santiago de Cuba: del "abandono" al perfeccionamiento en su sistema defensivo, siglos XVII- XVIII", Iberoamérica Social, Vol. 2, no especial (Sevilla, 2018), pp. 51-52.

${ }^{13}$ López Rodríguez, El Castillo del Morro de Santiago de Cuba..., p. 8; Blanes Martín, op. cit.; Ramón Gutiérrez, Fortificaciones en Iberoamérica. Madrid: El Viso, 2005, p. 141; Tamara Blanes Martín, Fortificaciones del Caribe. La Habana y Madrid: Editorial Letras Cubanas, 2001, pp. 65-75.

${ }^{14}$ Descripción chronográphica del puerto y baya de Santiago de Cuba, 1651, Archivo General de Indias (AGI), MP-Santo Domingo, 51.

15 Leví Marrero, Cuba: economía y sociedad. Madrid: Playor, 1975, Tomo III, p. 162; La obra de reconstrucción del castillo no concluiría hasta finales de siglo en tiempos del gobernador Sebastián de Arancibía. Castillo Meléndez, op. cit., pp. 379-383.
} 


\section{AMERICANISTAS}

Ignacio J. López Hernández

Alejandro O'Reilly y el ingeniero Beltrán Beaumont en Santiago de Cuba: causas y principios de un proyecto de fortificación frustrado (1764-1766).

\section{ISSN 1988-7868}

bahía con el fuerte de la Estrella y la batería de Santa Catalina, en sendos estrechamientos del mismo canal de acceso. A todo ello se sumaría en 1702 la plataforma de San Juan, más tarde llamada del Santísimo Sacramento- en un nivel intermedio entre el castillo de San Pedro y la batería de la Punta ${ }^{16}$. Por último, completaron el conjunto de fortificaciones santiaguero distintas torres vigías en puestos de desembarco cercarnos como los de Juragua y Cabañas (1649) ${ }^{17}$ y la construcción del castillo de San Francisco sobre la misma trama urbana de la ciudad (1668). ${ }^{18}$

Estas fortificaciones han de entenderse como respuesta al peligro que representaban principalmente piratas y corsarios, y nunca armadas ni ejércitos profesionales. Este hecho condicionó el grado de independencia del sistema fortificado caribeño de los siglos XVI y XVII con respecto a modelos europeos, muchos más desarrollados ${ }^{19}$. Sin embargo, con el siglo XVIII se asiste a un cambio de paradigma en la guerra americana, al integrarse el continente y, más particularmente, el Caribe como uno de los principales teatros bélicos del momento. Así, con el estallido de la Guerra del Asiento tiene desarrollo por primera vez un conflicto cuyo desencadenante y escenario estuvo en la región del Caribe y el golfo de México, en donde se desplegaron grandes escuadras y ejércitos nacionales. ${ }^{20} \mathrm{~A}$ estos problemas se enfrentaron el gobernador Francisco Cagigal de la Vega y el ingeniero Francisco de Langle con un nuevo plan de defensa que remodeló las fortificaciones previas. Debido a la premura con la que se ejecutaron los trabajos, tan solo correspondieron a obras permanentes la ampliación por la ladera sur de la plataforma intermedia y la construcción de la nueva batería de la

\footnotetext{
${ }^{16}$ Existe cierta confusión en la documentación acerca del nombre de esta plataforma intermedia, pues si bien se bautizó como de San Juan Bautista (Castillo Meléndez, op. cit., pp. 384-385), avanzado el siglo XVIII será llamada del Santísimo Sacramento, nombre que con anterioridad también ostentaba la plataforma de la Punta. Véase Explicacion del Plano Ydrográfico dela voca del Pto. de Santiago de Cuba, Antonio de Arredondo, 1740, CGE, Ar.j-t.10-c.2-298.

${ }^{17}$ Padrón Reyes, "Santiago de Cuba...", op. cit., p. 51.

${ }^{18}$ Castillo Meléndez, op. cit., pp. 403-412. Al respecto Fernández Martín dio a conocer nuevos datos sobre el origen de esta obra que serán publicados próximamente. Mercedes Fernández Martín, "La defensa interior de Santiago de Cuba: el castillo de San Francisco", en A Fortified Sea: The Defence of the Caribbean During the Eighteenth Century and its Precedents (Congreso internacional, Sevilla, 26 de septiembre de 2018).

${ }^{19}$ Rodolfo Segovia, El Lago de Piedra. La geopolítica de las fortificaciones españolas del Caribe. 15861786. Bogotá: El Áncora Editores, 2006, pp. 64-65.

${ }^{20}$ Jeremy Black, Warfare in the Eighteenth Century. Londres: Cassell, 1999.
} 


\section{AMERICANISTAS}

Ignacio J. López Hernández

Alejandro O'Reilly y el ingeniero Beltrán Beaumont en Santiago de Cuba: causas y principios de un proyecto de fortificación frustrado (1764-1766).

\section{ISSN 1988-7868}

Estrella, para lo que fue inhabilitada la antigua diseñada por Císcara. ${ }^{21} \mathrm{Al}$ margen de estas dos obras que redefinieron la estructura defensiva de la bocana de la bahía, el resto del plan recayó en obras de campaña. A pesar de que su naturaleza efímera ha propiciado su olvido, fueron sus trincheras y baterías de tierra y fajina las principales bazas de la defensa de la jurisdicción santiaguera. Así, se construyeron diferentes obras en varias de las playas cercanas a Santiago, trincheras en los caminos y una línea defensiva que adelantó el frente de campaña del castillo del Morro. ${ }^{22}$

Estas obras fueron del todo eficaces por adaptarse inteligentemente a la guerra a contrarreloj del Caribe, en la que los factores ambientales y las enfermedades tropicales impedían asedios formales, situación a la que la bisoña oficialidad británica no estuvo entonces prevenida. Para cuando la guerra de los Siete Años puso la isla de Cuba entre los objetivos británicos, las fuerzas atacantes diseñaron en La Habana un modelo de ataque mucho más complejo y cercano a las estrategias europeas. De esta manera hizo su primera aparición en América la guerra de minas, que acabó abriendo brecha en el básico frente de campaña del Morro, heredado del siglo XVI. ${ }^{23}$ Santiago, por su parte, tampoco presentó una mayor evolución en su sistema defensivo para hacer frente a la amenaza. Así trasciende por un dibujo inédito de Antonio Panón y Marín de 1763 en el que se representa a vista de pájaro las defensas de la boca del puerto (figura 1). Estas aún seguían dependiendo de las baterías y trincheras construidas 20 años antes, con leves mejoras como la habilitación de un pequeño foso con revellín en el hornabeque de fajinas de la línea defensiva de $1741 .^{24}$

\footnotetext{
${ }^{21}$ Ignacio J. López Hernández, "La defensa de Santiago de Cuba...", op. cit., pp. 185-187.

22 Ibídem, pp. 188-192. Esta perspectiva de estudio se ha ampliado a todo el contexto cubano, destacando la proyección de este análisis en el plan de defensa de Antonio de Arredondo para La Habana. Véase Ignacio J. López Hernández, "La Fortificación de campaña en el plan de defensa de la isla de Cuba durante la Guerra del Asiento", Revista de Indias (Madrid: 2021), en prensa. Arredondo también plantearía parcialmente este modelo defensivo durante las mismas fechas en Matanzas. Véase Ignacio J. López Hernández, Ingeniería e Ingenieros en Matanzas. Defensa y obras públicas entre 1693 y 1868. Sevilla: Athenaica, 2019, pp. 71-72.

${ }^{23}$ David Syrett, The siege and capture of Havana, 1762. Londres: Navy Records Society, 1970, pp. XXXIXXXII.

${ }^{24}$ Plano del castillo del Morro de la ciudad de Cuba, Antonio Panon y Marín, junio de 1763, Centro Geográfico del Ejército (CGE), Cartoteca, Ar.j-t.10-c.2-304.
} 


\section{ISSN 1988-7868}

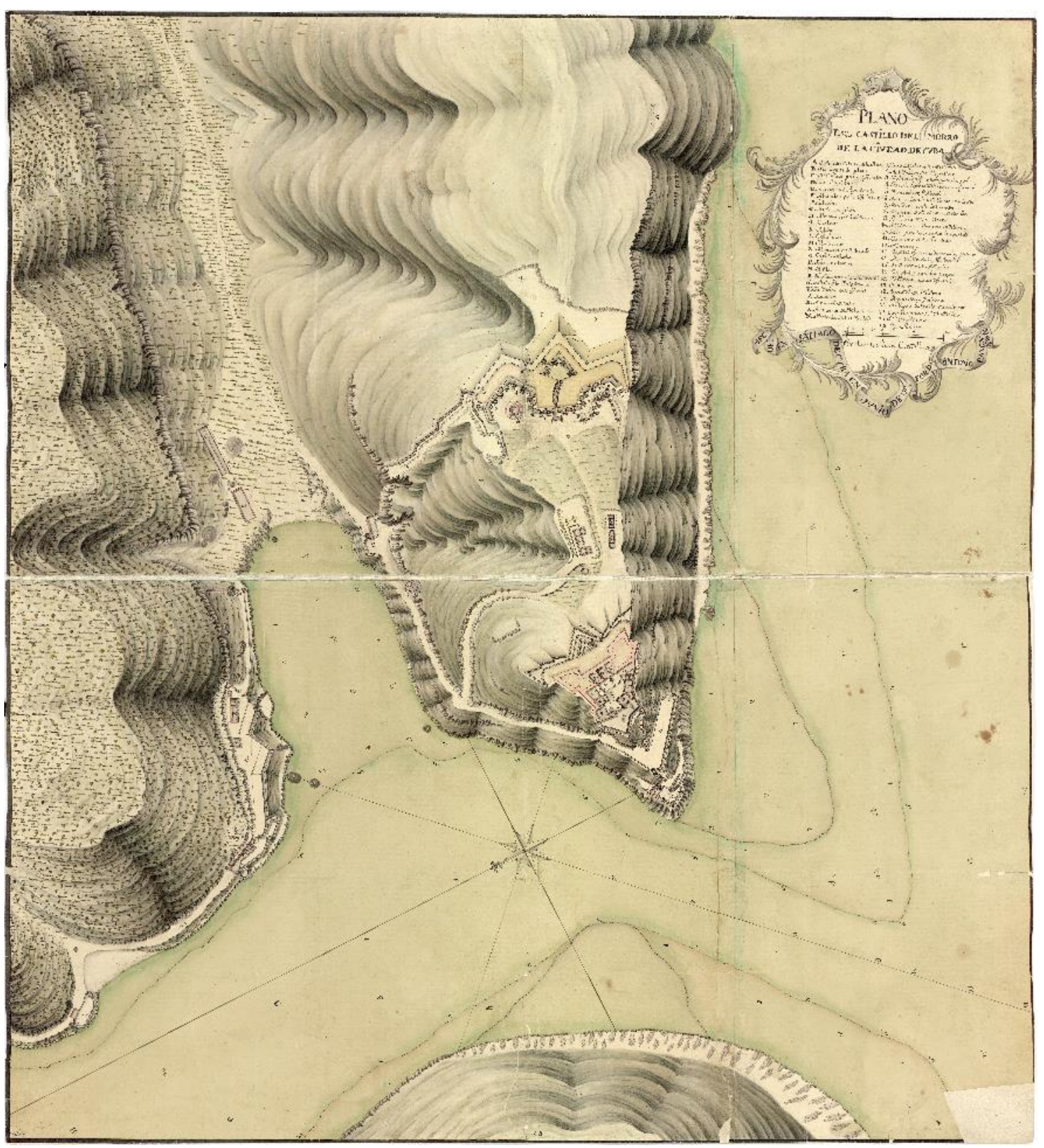

Figura 1. Plano del castillo del Morro de la ciudad de Cuba, Antonio Panon y Marín, junio de 1763, Centro Geográfico del Ejército (CGE), Cartoteca, Ar.j-t.10-c.2-304.

Un proyecto de fortificación para Santiago de Cuba de Alejandro O'Reilly y Beltrán

\section{Beaumont:}

Por fortuna para la gobernación santiaguera, la ciudad no fue atacada en aquella ocasión, sin bien quedó evidenciado, como lo fue en La Habana, que su sistema defensivo 


\section{AMERICANISTAS}

Ignacio J. López Hernández

Alejandro O'Reilly y el ingeniero Beltrán Beaumont en Santiago de Cuba: causas y principios de un proyecto de fortificación frustrado (1764-1766).

\section{ISSN 1988-7868}

debía someterse a una profunda revisión dentro de las reformas estructurales que le fueron encomendadas al conde de Ricla para el conjunto de la isla. Las diferentes comisiones serían repartidas entre un capacitado elenco de oficiales del que sobresalía el mariscal de campo Alejandro O'Reilly, designado inspector general de las milicias y destinado a suplir al mismo capitán general en caso de ausencia. ${ }^{25}$ La reforma de la organización militar de la isla y más particularmente la de sus milicias es reconocida como una de las grandes contribuciones de O'Reilly a la defensa de Cuba. ${ }^{26}$ Sin embargo, no solo fue esta misión la que lo ocupó en una larga expedición por los diferentes partidos de la isla entre 1763 y 1764. Al contrario de lo que concluye Torres Ramírez, se ha podido comprobar como O'Reilly adquirió ciertas competencias en las reformas del plan de fortificación de la isla. Si bien es cierto que su papel en las nuevas fortificaciones de La Habana se vio limitado por la fuerte personalidad del ingeniero director Silvestre Abarca, no fue así en otros proyectos formados a lo largo de la geografía insular y que fueron resultado de la citada expedición. Para ello se valió de la capacitación facultativa del ingeniero extraordinario Beltrán Beaumont, que lo acompañó "por orden del Exmo conde de Ricla a la importante comision y reconocimiento de los puestos de la Isla de Cuba (tanto a la banda del Norte como del Surd)". ${ }^{27}$

Muy poco es lo que se sabe hasta ahora de este ingeniero que llegó a Cuba junto a su hermano Pedro, también ingeniero extraordinario, en la misma expedición de Ricla y O'Reilly. ${ }^{28}$ De ambos se han hallado los planos de sus respectivos exámenes de ingreso al Cuerpo de Ingenieros en $1760,{ }^{29}$ poco antes de participar en la campaña de Portugal

\footnotetext{
25 Bibiano Torres Ramírez, Alejandro O'Reilly en las Indias. Sevilla: Escuela de Estudios Hispanoamericanos (CSIC), 1969, pp. 17-19. Este trabajo parte de otro anterior del mismo autor: Bibiano Torres Ramírez, "Alejandro O'Reilly en Cuba", Anuario de Estudios Americanos, no 24 (Sevilla, 1967), pp. $1-32$.

${ }^{26}$ Óscar Recio Morales, Alejandro O'Reilly, inspector general: Poder militar, familia y territorio en el reinado de Carlos III. Madrid: Sílex, 2020, pp. 105-125. Véase también Óscar Recio Morales, "Una aproximación al modelo del oficial extranjero en el ejército borbónico la etapa de formación del teniente general Alejandro O'Reilly (1723-1794)", Cuadernos Dieciochistas, no 12 (Salamanca, 2011), pp. 171-195. ${ }^{27}$ Explicacion de los proyectos de Santiago de Cuba, Beltrán y Pedro Beaumont, Madrid, 11 de septiembre de 1767, AGI, Santo Domingo, 2121.

${ }^{28}$ Pedro Cruz Freire, Silvestre Abarca. Un ingeniero militar al servicio de la monarquía hispana. Sevilla: Athenaica, p. 178.

${ }^{29}$ Plano de examen propuesto por la Dirección General de Fortificación, Beltrán Beaumont, 1760, Archivo General de Simancas (AGS), MPD, 31, 053; Proyecto de fortificación realizado para examen de ingreso en el Cuerpo de Ingenieros, Pedro Beaumont, 1760, AGS, MPD, 31, 054.
} 


\section{AMERICANISTAS}

\section{ISSN 1988-7868}

donde tomaron partido en algunas de las primeras victorias antes de tornarse en desastre. En ella, les fueron reconocidos méritos en las tomas de Salvaterra ${ }^{30}$ y Almeida, así como en la fortificación de Alfaiates. ${ }^{31}$ O'Reilly, que comandó parte del ejército en aquella campaña, debió entonces conocer a ambos ingenieros, pasando a América con la promesa de ascenso a la categoría de ingenieros ordinarios. Solo de esta forma se explica el grado de protección que brindarán tanto O'Reilly como Ricla a los hermanos Beaumont frente a la oposición y rechazo que, según se verá, les mostró continuamente su director Silvestre Abarca. $^{32}$

La comisión de O'Reilly y Beltrán Beaumont en Santiago de Cuba tuvo lugar entre finales de 1763 y principios del año siguiente. La primera determinación que tomaron fue la de ejecutar un exhaustivo reconocimiento de las fortificaciones de la bahía y sus contornos a fin de evaluar el estado de defensa de la plaza. De él se desprendió que todos los frentes del Morro y de sus baterías auxiliares exteriores, si bien no quedaban expuestos a un ataque marítimo, sí corrían el peligro de ser tomados por baterías terrestres como ocurrió en La Habana. ${ }^{33}$ Por su parte la campaña del castillo de San Pedro apenas podría repeler el mínimo ataque en atención a la reducida fuerza que acogería, comenzando por el estrechísimo camino cubierto, pasando por el pequeño revellín con el parapeto a la altura de la cintura y finalizando por los mismos baluartes de época de Antonelli, con una potencia de fuego reducida a tres cañones por cada cara y uno por flanco. ${ }^{34}$ Estas carencias básicas se sumaban a la insuficiente capacidad de acuartelamiento del castillo -el comandante y el capellán vivían fuera de él-, la debilidad de los parapetos y, sobre todo, y más trascendentemente, la existencia de ángulos muertos desde donde el enemigo podía situar baterías sin ser visto. Este problema ya fue advertido por el ingeniero Francisco de Langle, lo que motivó la construcción de la línea de defensa exterior del castillo a modo

\footnotetext{
${ }^{30}$ Plano de la Plaza y Castillo de Salvatierra antes de su demolición, Pedro y Beltrán Beaumont, 1762, CGE, Cartoteca, Ar.G bis-T.6-C.4-128.

${ }^{31}$ Beltrán y Pedro Beaumont a Julián Arriaga, Santiago de Cuba, 17 de diciembre de 1765, AGI, Santo Domingo, 2121.

${ }^{32}$ Descargos de los dos ingenieros extraordinarios de los reales exercitos tocante la comision de dirigir las obras proyectadas de Santiago de Cuba, Pedro y Beltrán Beaumont, Madrid, 11 de septiembre de 1767, AGI, Santo Domingo, 2121.

${ }^{33}$ Manifiesto por el qual se haze conocer la flaqueza del Morro de Santiago de Cuba y sus obras exteriores, Beltrán y Pedro Beaumont, Santiago de Cuba,16 de junio de 1765, AGI, Santo Domingo, 2121.

34 "Defectos del frente del Castillo del Morro", Ibídem.
} 


\section{AMERICANISTAS}

Ignacio J. López Hernández

Alejandro O'Reilly y el ingeniero Beltrán Beaumont en Santiago de Cuba: causas y principios de un proyecto de fortificación frustrado (1764-1766).

\section{ISSN 1988-7868}

de campo atrincherado, de cuyo sistema destacaba el citado hornabeque de tierra y fajina que fue ligeramente perfeccionado hacia 1762 con motivo de la guerra. Sin embargo, O'Reilly y Beaumont advirtieron que su construcción y diseño eran completamente anómalos: resultaba pequeño, sin potencia de fuego suficiente, sin camino cubierto ni glacis y su escarpa era de menor tamaño que la de un hombre, de forma que servía más como espaldón del enemigo frente a los fuegos del castillo que como primera línea de defensa. ${ }^{35}$

No obstante, aun cuando el frente quedara perfectamente diseñado, sus fuegos se encontraban ligeramente dominados por el monte de la Estrella, a cuyos pies se hallaba la batería del mismo nombre. Una vez más se hace evidente cómo el ataque británico en La Habana previno de peligros antes completamente ignorados: "y en fin expuesto a los fuegos del Monte de la Estrella que es una Cabaña respecto a essas fortalezas del Morro, como la Cabaña hablando de l'Havana era antes que se fortificasse". ${ }^{36} \mathrm{El}$ mismo problema presentaba el monte de la Socapa, que ceñía la bocana de la bahía frente al castillo de San Pedro. Mediante la construcción de pequeñas baterías sería posible para el enemigo dominar las tres plataformas escalonadas del Morro y rendir el fuerte sin ninguna oposición. ${ }^{37}$

De este reconocimiento O'Reilly y Beaumont concluyeron que, como en el caso habanero, la solución pasaba por ocupar estos enclaves dominantes con nuevas obras que se integrarían en un plan de defensa general en el que las fortificaciones se cubrirían mutuamente, de modo que nunca la toma de alguna de ellas conllevara la capitulación de la plaza. Comenzando por el frente de campaña del castillo de San Pedro, ambos oficiales plantearon la posibilidad de aplicar principios ya clásicos de la fortificación de Vauban con los que se estaba trabajando en San Carlos de la Cabaña, adicionándole al fuerte un nuevo revellín y sendas contraguardias. Sin embargo, este adelantamiento del frente seguía sin abrirse a los ángulos muertos denunciados por ambos, por lo que finalmente

\footnotetext{
35 "De la trinchera provisional", Ibídem.

${ }^{36}$ Descargos de los dos ingenieros..., Pedro y Beltrán Beaumont, Madrid, 11 de septiembre de 1767, AGI, Santo Domingo, 2121.

37 "Defectos de las demas partes del Castillo", en Manifiesto..., Beltrán y Pedro Beaumont, Santiago de Cuba, 16 de junio de 1765, AGI, Santo Domingo, 2121.
} 


\section{AMERICANISTAS}

Ignacio J. López Hernández

Alejandro O'Reilly y el ingeniero Beltrán Beaumont en Santiago de Cuba: causas y principios de un proyecto de fortificación frustrado (1764-1766).

\section{ISSN 1988-7868}

propusieron la sustitución del hornabeque de tierra y fajina de 1741 por una nueva obra permanente, pues "aunque la direccion de sus partes y construccion no valia nada y que era muy perjudical al castillo del Morro, nobstante la posicion era excelente". ${ }^{38}$ Con ello se adelantaba más de 250 metros la primera línea de defensa del castillo, ganándose así espacio para construcción de almacenes para pertrechos y víveres, un nuevo aljibe, un hospital, una capilla y una caballeriza para una compañía. La nueva fortificación habría de construirse a prueba de bomba a fin de aumentar el acuartelamiento del castillo hasta los 800 o 1000 hombres. La memoria que sirve de referencia para conocer el proyecto, escrita por los hermanos Beaumont a modo de resumen tres años después de su redacción, elude algunos datos acerca de la estructura de la obra. Salva esta laguna el hallazgo de varios de los planos originales del proyecto -desgajados y sin vínculo documental-en diferentes archivos militares españoles. Aunque no se cuenta con ninguna planta de la fortificación de avanzada, es posible precisar su estructura por una serie de perfiles sobre el terreno que complementan el Plano proyecto para la recomposicion del Morro. ${ }^{39}$ En él se contiene la Explicación del Perfil que passa por la linea 2,3,4,5 donde se muestra el corte de un bastión con el referido alojamiento de la tropa en una bóveda a prueba de bomba, al tiempo que se indica la ubicación de la antigua trinchera, casi descompuesta y sobre la que habría de construirse la nueva fortificación. Por otro perfil distinto contenido en un nuevo plano se averigua además que frente a esta construcción se abriría un foso con un revellín, lo que permite suponer que la obra seguiría a gran tamaño el esquema de hornabeque de la fortificación de campaña de 1741 (figura 2). ${ }^{40}$

\footnotetext{
${ }^{38}$ Explicacion de los proyectos de Santhiago de Cuba, Beltrán y Pedro Beaumont, Madrid, 11 de septiembre de 1767, AGI, Santo Domingo, 2121.

39 "Perfiles del Castillo de El Morro para su proyecto de reconstrucción", Beltrán Beaumont, Archivo General Militar de Madrid (AGMM), Cartoteca, CUB-39/13.

${ }^{40}$ Perfil que Passa por la linea 1,2,3,4,5,6,7 desde el Morro a la pequeña altura z.f, Beltrán Beaumont, CGE, Cartoteca, Ar.j-t.10-c.2-31.
} 


\section{ISSN 1988-7868}

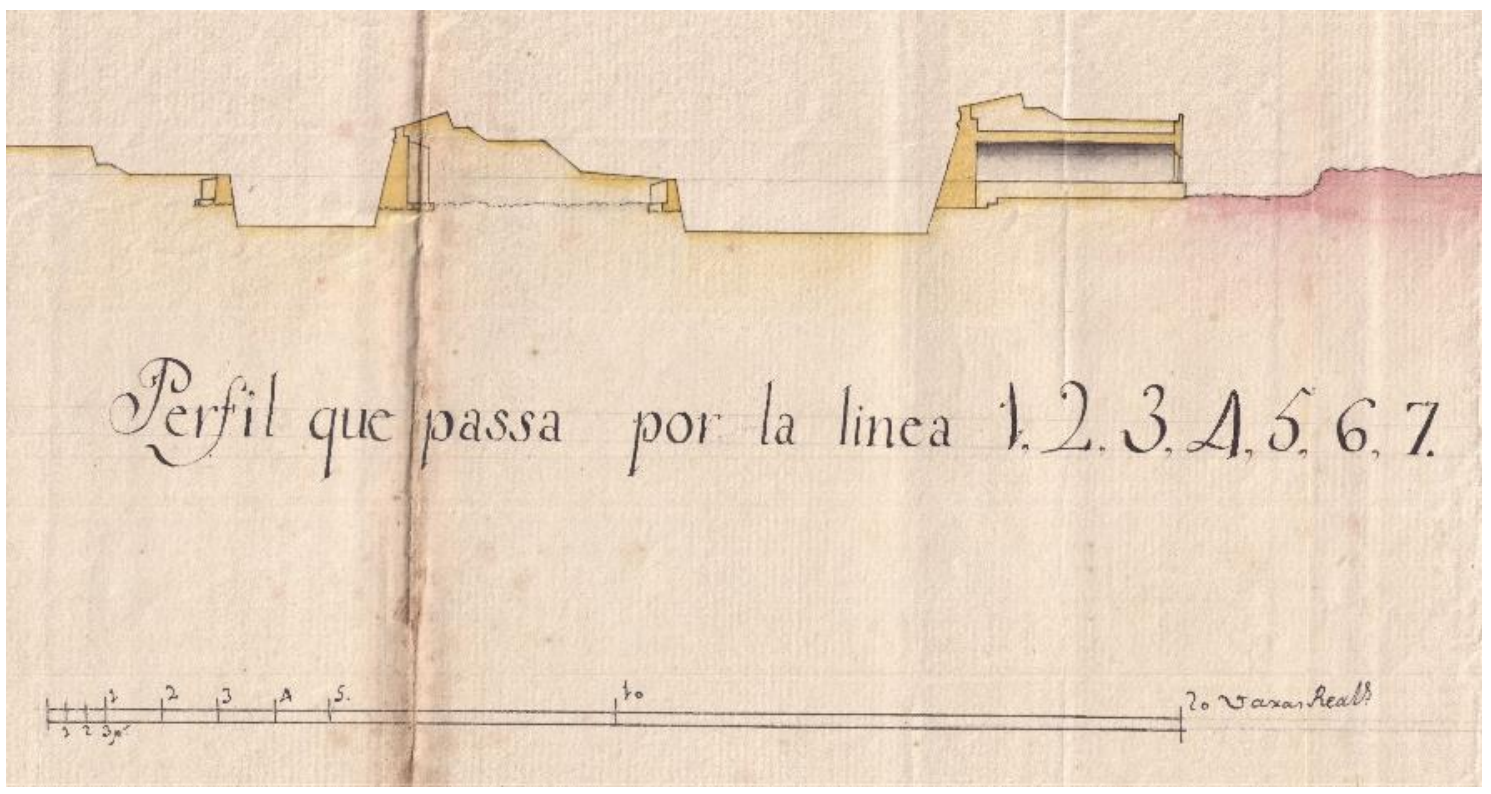

Figura 2. Perfil que Passa por la linea 1,2,3,4,5,6,7 desde el Morro a la pequeña altura z.f, Beltrán Beaumont, CGE, Cartoteca, Ar.j-t.10-c.2-31.

Esta obra permitiría controlar cualquier punto de acceso a la colina del Morro y haría prácticamente inviable su capitulación para el enemigo. Sí presentaba un punto débil al quedar ligeramente dominada por el monte de la Estrella, pues en caso de que fuera tomado por las fuerzas atacantes, sería cuestión de tiempo la rendición del Morro. Para evitarlo, Beaumont y O'Reilly planearon abrir baterías por el frente norte que mira hacia la Estrella, creando un cinturón amurallado que cercaría la obra antigua del Morro:

En cazo de aproderarse el enemigo del Monte de la Estrella [...], el frente maior de la expressada obra que abraza el castillo del Morro que mira directamente a essa parte, ofrece por su capacidad una formidable artilleria [...] Tambien tiene la ventaja de ofrecer asy al mar una gran bateria alta [caballero] y baxa que ofenden a los navios que intentasse aproximarse del fuerte y castillo del Morro para bombardearlos y forcejar el Puerto. ${ }^{41}$

${ }^{41}$ Explicacion de los proyectos..., Beltrán y Pedro Beaumont, Madrid, 11 de septiembre de 1767, AGI, Santo Domingo, 2121. 


\section{AMERICANISTAS}

\section{ISSN 1988-7868}

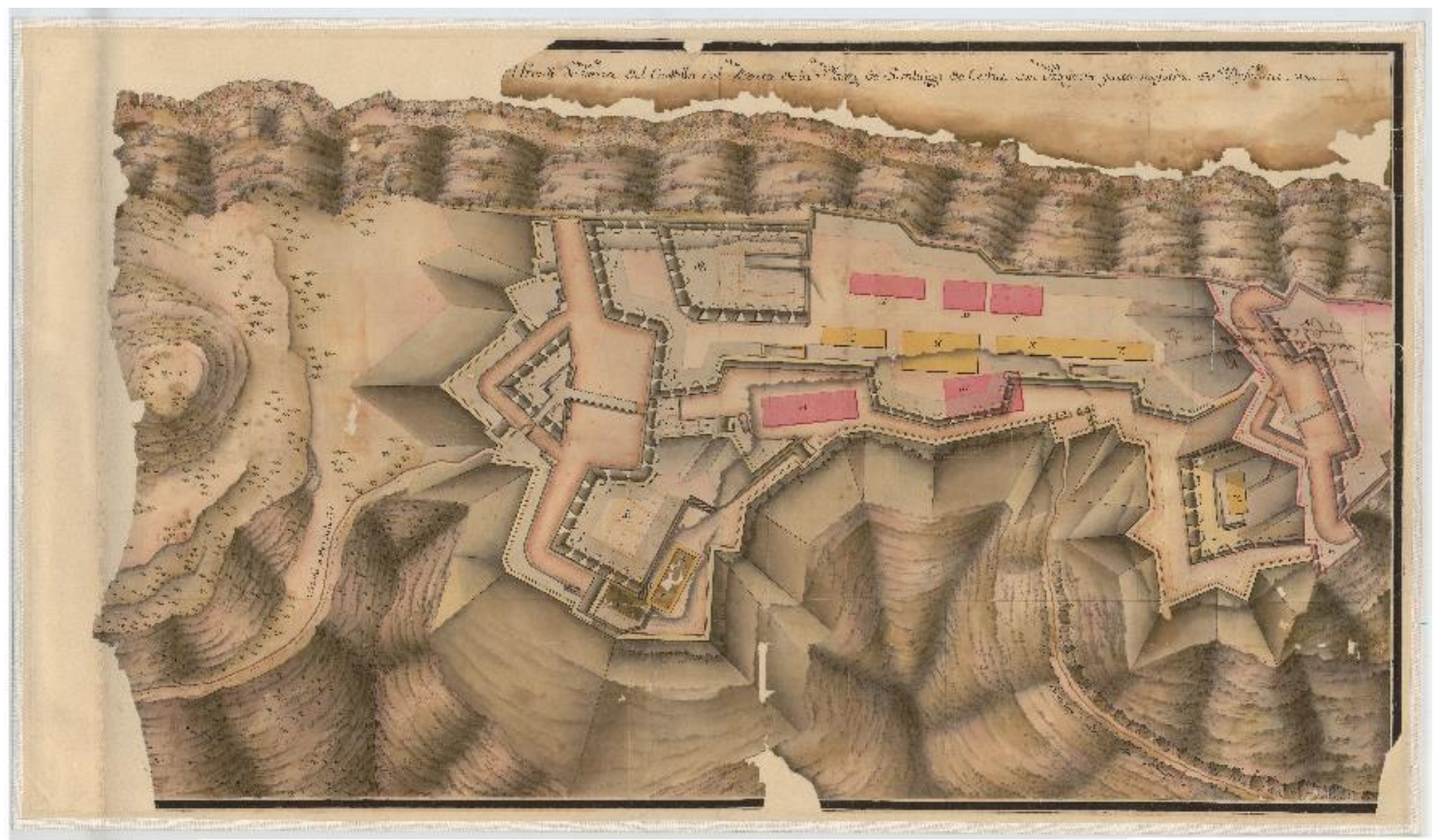

Figura 3. Plano que manifiesta el frente de tierra del castillo del Morro, de la plaza de Santiago de Cuba, Ventura Buceta, h. 1775, AGMM, Cartoteca, CUB-91/02

Con estos datos es posible ahora vincular, con prudencia, este proyecto con un plano de hacia 1775 del ingeniero militar Ventura Buceta en el que muestra "el frente de tierra del castillo del Morro de la Plaza de Santiago de Cuba con Proyecto para mejorar su defensa"42. Aunque con toda probabilidad se trata de una reinterpretación del proyecto de Beaumont y O'Reilly con modificaciones y añadidos, en el plano se advierten claramente elementos como el frente del hornabeque con su caballero y revellín, las baterías del frente norte y los nuevos alojamientos interiores (figura 3).

\footnotetext{
${ }^{42}$ Plano que manifiesta el frente de tierra del castillo del Morro, de la plaza de Santiago de Cuba, Ventura Buceta, h. 1775, AGMM, Cartoteca, CUB-91/02; Perfiles y vistas correspondtes. al Castillo del Morro dela plaza de Cuba y terreno de su inmediacion, Ventura Buceta, h. 1775, AGMM, Cartoteca, CUB-46-23.
} 


\section{ISSN 1988-7868}

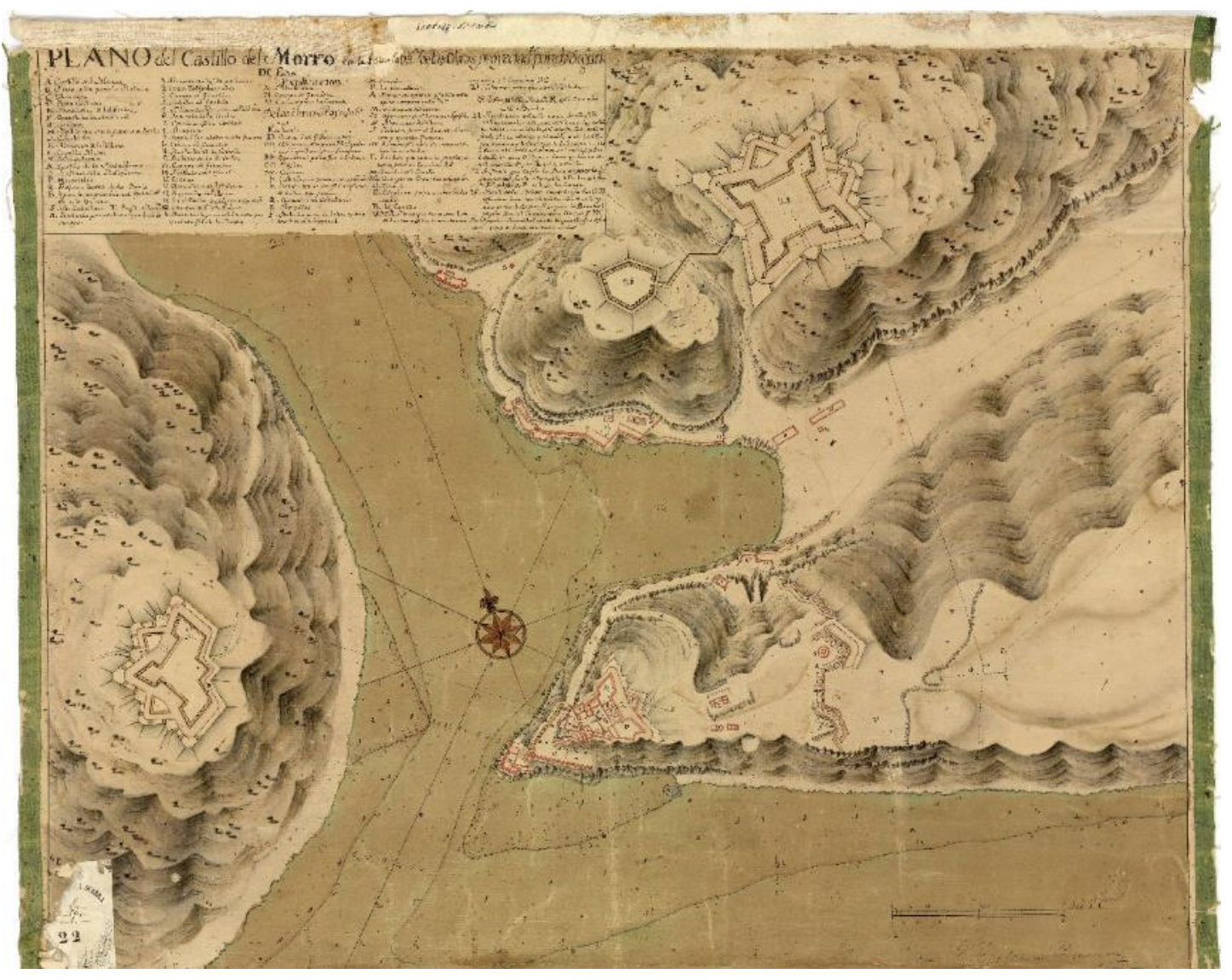

Figura 4. Plano del Castillo del Morro en la Isla Cuba Y de las Obras proyectadas para la Segurida, Beltrán Beaumont, h. 1764, CGE, Cartoteca, Ar.j-t.10-c.2-296.

El plan de fortificación se completaba con la construcción de otros fuertes en las lomas de la Estrella y la Socapa, de los que sí se cuenta con mayor información gráfica gracias a un plano general de la entrada a la bahía firmado por Beltrán Beaumont, hallado en el Centro Geográfico del Ejército (figura 4). ${ }^{43}$ En el caso de la colina que hacía frente al Morro, los oficiales proponían construir una obra coronada, no tanto por la necesidad de redoblar la potencia de fuego sobre el canal de acceso como por evitar el establecimiento de baterías de campaña por parte del enemigo. Así se desprende de su diseño, al presentar más artillería por su frente de tierra que por el marítimo. Complementariamente, el fuerte daría apoyo a las posibles tropas que se encontraran en

43 Plano del Castillo del Morro en la Isla Cuba Y de las Obras proyectadas para la Segurida, Beltrán Beaumont, h. 1764, CGE, Cartoteca, Ar.j-t.10-c.2-296. 


\section{AMERICANISTAS}

Ignacio J. López Hernández

Alejandro O'Reilly y el ingeniero Beltrán Beaumont en Santiago de Cuba: causas y principios de un proyecto de fortificación frustrado (1764-1766).

\section{ISSN 1988-7868}

retirada desde alguno de los puestos de control de la costa occidental como Cabañas o Bueycabón, evitando un rodeo de ocho a diez leguas hasta la ciudad. ${ }^{44}$

Por su parte y fundamentándose en principios similares, el monte de la Estrella sería fortificado con un gran cuadrado abaluartado clásico. ${ }^{45}$ Una vez más, su función principal fue la de controlar y evitar la toma de aquel enclave crítico para las fortificaciones del Morro y sobre todo para la batería baja de la Estrella. Con él además se multiplicarían los frentes atacables en combinación con las nuevas fortificaciones del Morro, obligando al enemigo a establecer dos sitios formales simultáneos y dividir su potencia ofensiva. Beaumont destacó su inteligente diseño, en el que la capital del baluarte más próximo a las baterías del Morro enfilaba directamente aquella fortificación, de manera que sus cañones nunca podrían utilizarse en su contra en caso de que el fuerte fuera tomado por los atacantes. ${ }^{46}$ La obra se reforzaba con una pequeña batería pentagonal -no abaluartada- comunicada con el fuerte principal que, controlando una pequeña depresión del terreno, imposibilitaba un golpe de mano en la batería baja de la Estrella, al tiempo que sus fuegos flanqueaban las demás fortificaciones proyectadas. ${ }^{47}$

\section{El fracaso del proyecto: entre enfrentamientos personales y desacuerdos técnicos y estratégicos.}

El proyecto fue remitido a la corte para su evaluación, siendo finalmente aprobado y mandado ejecutar mediante Real Orden de 30 de agosto de 1764, por la cual además se prevenía a Ricla la libranza de la parte proporcional que considerara oportuna sobre los

\footnotetext{
${ }^{44}$ Propiedades de la obra coronada proyectada sobre el Monte de la socapa por el exmo Dn Alexandro OReily y el Ingeniero, en Explicacion de los proyectos..., Beltrán y Pedro Beaumont, Madrid, 11 de septiembre de 1767, AGI, Santo Domingo, 2121.

45 Plano del Castillo del Morro en la Isla Cuba ..., CGE, Cartoteca, Ar.j-t.10-c.2-296.

46 "La disposicion y direccion del fuerte quadrado sobre el monte de la estrella ofrece la capital de uno de sus angulos, de tal suerte dispuesta que aunque el enemigo llegasse a apoderarse de dicho fuerte, ninguno de sus frentes les puede servir para batir el Castillo del Morro y su obra avanzada". Razones que motivaron al Exmo. Dn Alexandro O'Reily y al Ingeniero a establecer un fuerte Quadrado sobre el monte de la Estrella, en Explicacion de los proyectos..., Beltrán y Pedro Beaumont, Madrid, 11 de septiembre de 1767, AGI, Santo Domingo, 2121. En términos de geometría y diseño de fortificaciones, la capital de un baluarte es la línea imaginaria que lo divide en dos partes simétricas.

${ }^{47}$ De la bateria pentagonal, Ibídem.
} 


\section{AMERICANISTAS}

Ignacio J. López Hernández

Alejandro O'Reilly y el ingeniero Beltrán Beaumont en Santiago de Cuba: causas y principios de un proyecto de fortificación frustrado (1764-1766).

\section{ISSN 1988-7868}

500.000 pesos ya destinados a la fortificación de la isla. ${ }^{48}$ Para ponerlo en marcha, O'Reilly y Ricla comisionaron la ejecución del proyecto a Beltrán y Pedro Beaumont, a pesar de las reticencias iniciales de los ingenieros a ser elegidos. Resulta extraño a priori que el encargo de uno de los proyectos de fortificación más ambiciosos de la isla recayera sobre dos ingenieros de clase "extraordinario", si bien parece que esa negativa inicial venía motivada por asuntos de índole personal. Así se llega a intuir en el mismo nombramiento hecho por Ricla para aquella misión:

Deberan Vuestras Mercedes demarchar en el termino de quatro diaz para Cuba por combernirlo al Real servicio y admitir essa comission por su propia reputacion por exigirlo el servicio del Rey por la Patria, los habitantes y sus mismos ascenssos y aunque se me izo de por parte de sus jefes una fuerte representacion para que la eleccion recayera en otros, no quise assentir a su proposicion no solo por conocer su intelligencia conducta y desinteres cuyo informe e dado en la corte sino por aver echo tan bien uno de ustedes los proyectos, nadie puede ponerlos mexor en execucion. ${ }^{49}$

La aludida oposición al nombramiento de ambos venía del ingeniero director Silvestre Abarca, quien, como llega a intuir Torres Ramírez, no profesaba un sentimiento muy cordial por el protector de ambos ingenieros Alejandro O'Reilly ni, como se desprende, por el mismo conde de Ricla. Parece que las desavenencias entre ellos tuvieron su origen en la negativa de Abarca a dejarse supervisar por ambos superiores. O'Reilly llegó a insinuar que el director de ingenieros pretendía la gobernación de La Habana, por quedar sujeta su seguridad a las obras que entonces se ejecutaban. ${ }^{50}$ Esta tensa relación se demuestra por diversos episodios de los que fueron partícipes los hermanos Beaumont y que son relatados por estos para descargarse de las posibles acusaciones o represalias

\footnotetext{
${ }^{48}$ Aunque no se ha localizado la referida real orden, son varias las alusiones a su existencia, siendo la más precisa la que comunica el gobernador de Santiago al capitán general de la isla. El marqués de Casa Cagigal a Bucareli, Santiago de Cuba, 7 de mayo de 1766, AGI, Cuba, 1051, Carta 9; El conde de Ricla a Arriaga, La Habana, 3 de febrero de 1765, AGI, Santo Domingo, 2120.

${ }^{49}$ El conde de Ricla a Beltrán y Pedro Beaumont, La Habana, abril de 1765, AGI, Santo Domingo, 2121.

${ }^{50}$ Torres Ramírez, Alejandro O'Reilly en las Indias..., pp. 47-48.
} 


\section{AMERICANISTAS}

Ignacio J. López Hernández

Alejandro O'Reilly y el ingeniero Beltrán Beaumont en Santiago de Cuba: causas y principios de un proyecto de fortificación frustrado (1764-1766).

\section{ISSN 1988-7868}

motivadas por el fracasado plan de defensa de Santiago. ${ }^{51}$ Así, a su llegada a La Habana, fueron a ver a Abarca, quien los previno de no visitar ni a O'Reilly ni a Mateo de Villamayor, secretario del conde de Ricla bajo la justificación de que "no combenia que essos sugetos se mesclassen en asumpto de las obras de fortificacion que se debian emprender". Ambos se negaron a cumplir aquella orden, lo que desencadenaría la aversión hacia ellos por parte de Abarca. Este último, según relatan los ingenieros, los acusó de estar detrás de las discusiones que tanto Ricla como O'Reilly mantuvieron con Abarca sobre el correcto diseño de las fortificaciones. ${ }^{52}$

Este conflicto sirve asimismo para graduar el concepto que O'Reilly tenía de la figura del ingeniero como facultativo subordinado a los mayores conocimientos estratégicos de sus generales. De este modo, la proyección y construcción de fortificaciones requería de una intervención expresa de quienes sabían de manera más amplia del arte de la guerra. ${ }^{53}$ Esta subordinación, acompañada de los necesarios conocimientos técnicos, era la que proporcionó Beltrán Beaumont a Alejandro O'Reilly en su reconocimiento de la isla y más particularmente en el proyecto de fortificación de Santiago de Cuba. Por su parte, la designación de los dos hermanos para dirigir las obras aseguraba que el proyecto, al contrario de lo que ocurría en La Habana, sería controlado por la capitanía general. Solo de esta forma se explica el hecho de que el proyecto fuera cursado directamente al secretario de estado Julián Arriaga para su evaluación y posterior aprobación por el rey, sin haber mediado en él las habituales enmiendas de la máxima autoridad del Cuerpo de Ingenieros en la isla.

Beltrán y Pedro Beaumont eran conscientes de que su operatividad dependía completamente de la mediación de ambos superiores, por lo que antes de aceptar la

\footnotetext{
${ }^{51}$ Descargos de los dos ingenieros..., Pedro y Beltrán Beaumont, Madrid, 11 de septiembre de 1767, AGI, Santo Domingo, 2121.

52 "Ofrecieronse varios debates el Exmo. Conde de Ricla y el Exmo. Dn Alexandro OReily con el Director en asumpto de fortificaciones especialmente sobre la colocacion de cierta bateria infirieron los gefes que eran por las influencias de los dos Ingenieros Hermanos naturalmente por que los veian tratados con la maior distincion de dichos Exmos [...] y dieron por lo tanto en mortificarles en su servicio usando con ellos la maior inconsideracion hasta preferir en las obras a los Ingenieros Voluntarios y dar directamente las ordenes a los maestros Albañiles sin comunicarseles". Ibídem.

53 Torres Ramírez, Alejandro O'Reilly en las Indias..., pp. 47-48.
} 


\section{AMERICANISTAS}

Ignacio J. López Hernández

Alejandro O'Reilly y el ingeniero Beltrán Beaumont en Santiago de Cuba: causas y principios de un proyecto de fortificación frustrado (1764-1766).

\section{ISSN 1988-7868}

comisión en Santiago de Cuba, intentaron desposeerse de aquella responsabilidad. Lo hacían sabedores de que, una vez sus protectores volvieran a la península, tanto el proyecto como su dirección facultativa serían boicoteados. Aquellos augurios se cumplieron con precisión a partir del día 26 de junio de 1765 en el que Ricla dejó la capitanía general de la isla. Desde entonces, los ingenieros denunciaron que los dos meses de buenas relaciones con el gobernador de Santiago de Cuba, el marqués de Casa Cagigal, dieron paso a continuos obstáculos, según estos por su aversión personal contra el mariscal O'Reilly:

Conociendo con evidencia lo vendida que esta su plaza [...] nos da a presumir que no quiere que esto se fortifique lo uno por no ser parto suyo, lo segundo por ser enemiguissimo del Sr Dn Alexandro OReilly y lo otro para que no sea dicho que todo quanto a echo su tio no vale nada. ${ }^{54}$

Aún con la distancia con la que se deben interpretar estas declaraciones parciales, la última de las referencias hacía mención de un hecho real y que supuso el principal objeto de la disputa entre los ingenieros y el gobernador. Los trabajos debían comenzar por la cimentación de la obra avanzada del castillo del Morro, para lo que era requisito indispensable el derribo del antiguo hornabeque de tierra y fajina que se construyó en 1741 por orden de Francisco Cagigal de la Vega, tío del gobernador. Al negarse este último, no por causas familiares sino puramente estratégicas, los ingenieros elevaron el asunto al nuevo capitán general interino Pascual Cisneros, que lo derivó a la corte para su resolución. ${ }^{55}$ Mientras esta llegaba, y siempre según el testimonio de los hermanos ingenieros, estos sufrirían continuos obstáculos durante el aprovisionamiento de materiales e incluso la supuesta manipulación por parte de Abarca de los inventarios remitidos a La Habana. ${ }^{56}$

\footnotetext{
${ }^{54}$ Beltrán y Pedro Beaumont a Arriaga, Santiago de Cuba, 17 de diciembre de 1765, AGI, Santo Domingo, 2121.

${ }^{55}$ Cisneros a Arriaga, La Habana, 30 de noviembre de 1765, AGI, Santo Domingo, 2121.

56 "[... pues si en el de los Ingenieros que debian mandar en Cuba, pedian 2000 de una coza, [el director] quitava un zero se reducia a 200, si 100 de otra quedava en 10 y todo a este tenor, de conformidad que según el Estado Verdadero venia a ser un estado provisional y según el segundo apenas avia para fabricar
} 


\section{AMERICANISTAS}

Ignacio J. López Hernández

Alejandro O'Reilly y el ingeniero Beltrán Beaumont en Santiago de Cuba: causas y principios de un proyecto de fortificación frustrado (1764-1766).

\section{ISSN 1988-7868}

Con la llegada de Antonio María Bucareli a la capitanía general y coincidiendo con el devastador terremoto del 11 de junio de 1766 que arruinó parte de las fortificaciones de la bahía, el marqués de Casa Cagigal aprovechó para solicitar el relevo de los ingenieros y el envío del coronel Agustín Crame. La petición del gobernador partía de un informe de los hermanos Beaumont sobre el estado en que quedaron las fortificaciones. ${ }^{57}$ Cagigal consideró la situación más grave que la descrita por los ingenieros en su informe y pidió que se encargara de ello Crame, por entonces ocupado en los trabajos de conclusión del castillo de Atarés. ${ }^{58}$ El capitán general respondió afirmativamente, primero relevando a los Beaumont y enviando al ingeniero Juan de Cotilla, ${ }^{59}$ para más tarde destinar a Crame a Santiago para los referidos reconocimientos. ${ }^{60}$

No es posible precisar si la crítica de Cagigal a la inspección hecha por los hermanos Beaumont fue una mera excusa, si bien la evaluación de Crame no reveló cambios sustanciales con respecto a la de aquellos. ${ }^{61}$ El informe de Crame vino acompañado de un proyecto de reconstrucción del castillo en el que se mantuvo la misma distribución de elementos con la salvedad de incluir bóvedas a prueba de bombas en los alojamientos superiores. ${ }^{62}$ Sin embargo, lo que en realidad trascendería del reconocimiento de Crame será el olvido definitivo del proyecto de O'Reilly y Beltrán Beaumont, tras la dura crítica a la que lo someterá: "sentiré hacer memoria del proyecto anterior, lleno de imperfecciones capitales y que no es conveniente ni adaptable al terreno". ${ }^{63}$ Según Crame, la invalidez del plan partía de un incorrecto reconocimiento del paraje, habiéndose cometido errores graves en la medición y situación sobre plano de sus

\footnotetext{
un reducto pequeño", Descargos de los dos ingenieros..., Pedro y Beltrán Beaumont, Madrid, 11 de septiembre de 1767, AGI, Santo Domingo, 2121.

57 Reconocimiento hecho por nos Dn Beltran y d Pedro Beaumont Yngenieros Extraordinarios de SM, Beltrán y Pedro Beaumont, Santiago de Cuba, 13 de junio de 1766, AGI, Cuba, 1051, Carta 13A.

${ }^{58}$ Cagigal a Bucareli, Santiago de Cuba, 26 de junio de 1766, AGI, Cuba, 1051, Carta 18.

${ }^{59}$ Cagigal a Bucareli, Santiago de Cuba, 17 de agosto de 1766, AGI, Cuba, 1051, Carta 29.

${ }^{60}$ Cagigal a Bucareli, Santiago de Cuba, 14 de septiembre de 1766, AGI, Cuba, 1051, Carta 39.

${ }^{61}$ Crame a Bucareli, Santiago de Cuba, 18 de septiembre de 1766, AGI, Cuba, 1070, fols 7r-11v.

${ }^{62}$ Crame a Bucareli, La Habana, 23 de enero de 1767, AGI, Cuba, 1070, fols. 12r-19v; Perfiles del Castillo del Morro de la Ciudad de Santiago de Cuba, Agustín Crame, 23 de enero de 1767, Archivo General Militar de Madrid (AGMM), Cartoteca, CUB-145/08. Existe copia del mismo plano en AGI, MP-Santo Domingo, 344. Sobre el proyecto de Crame en conflicto con la corrección posterior de Cermeño puede consultarse Ignacio J. López Hernández, "Crame, Cermeño y la reforma del Morro de Santiago de Cuba (1766-1767)", Quiroga. Revista de Patrimonio Iberoamericano, no 19 (Granada, 2021), pp. 88-101.

${ }^{63}$ Crame a Bucareli, Santiago de Cuba, 18 de septiembre de 1766, AGI, Cuba, 1070, fols 7r-11v.
} 


\section{AMERICANISTAS}

Ignacio J. López Hernández

Alejandro O'Reilly y el ingeniero Beltrán Beaumont en Santiago de Cuba: causas y principios de un proyecto de fortificación frustrado (1764-1766).

\section{ISSN 1988-7868}

diferentes accidentes geográficos. ${ }^{64}$ Así, indica que la bocana de la bahía era dieciséis varas más amplia que la descrita por el proyecto anterior, ubicándose por su parte la Socapa en una posición más al norte. Un problema similar presentaba el reconocimiento del monte de la Estrella, distante 800 varas del frente de tierra del Morro. Como consecuencia, Crame no creyó necesaria la construcción de los fuertes proyectados por el mariscal y su ingeniero. Tan solo el nuevo frente de campaña propuesto, que Crame describió como "quadrilongo avanzado", mereció algo de reconocimiento por su diseño. ${ }^{65}$ No obstante, criticó lo que a ojos de O'Reilly y Beaumont era su principal ventaja, pues aumentaba excesivamente el recinto y su necesaria guarnición.

Sin embargo, en el dictamen de Crame y su sencilla propuesta de intervención subyace otra causa de naturaleza geoestratégica, del todo radical. El coronel acabó proponiendo el abandono de la ciudad y posterior voladura de sus fortificaciones. Su razonamiento yacía en la consideración de que nunca sería posible asegurar la ciudad debido a la multiplicidad de sus frentes, de los que la entrada a la bahía era tan solo uno de ellos. ${ }^{66}$ Por su parte, el esfuerzo al que se veía obligada la administración contrastaba con la insignificancia de su vecindario y la pobreza de su comercio. En este sentido, la principal medida que podía tomarse con respecto a la defensa de la ciudad era evitar que el enemigo se hiciera fuerte en ella usando sus fortificaciones, pues cualquier mejora que se hiciera en ellas no paliaría la exposición de la ciudad. Esto fue algo ya advertido en el plan de defensa de 1741, lo que obligó a fortificar las playas de la jurisdicción. Sin embargo, lo que por entonces resultó efectivo según se demostró en los dos ataques que sufrió Santiago en 1741 y 1748, ya no tenía vigencia con las mejoras tácticas que incorporaron los británicos en la guerra del Caribe. ${ }^{67}$ Así, el hecho de que Santiago pasara desapercibida para el enemigo en la pasada guerra solo probaba el desinterés estratégico de aquel enclave para sus aspiraciones. ${ }^{68}$ En cambio, más práctico resultaría el traslado

\footnotetext{
${ }^{64}$ Crame a Bucareli, La Habana, 23 de enero de 1767, AGI, Cuba, 1070, fols. 12r-19v.

${ }^{65}$ La descripción concuerda con el plano de Ventura Buceta que aquí se vinculó con el diseño final del proyecto de O'Reilly y Beaumont.

${ }^{66}$ Crame a Bucareli, La Habana, 23 de enero de 1767, AGI, Cuba, 1070, fols. 17r-19v.

67 "No son passos precisos los que se han tenido por tales para detener con trincheras a un enemigo superior", Ibídem.

${ }^{68}$ Crame a Bucareli, Santiago de Cuba, 27 de julio de 1767, AGI, Cuba, 1070, Carta 15.
} 


\section{AMERICANISTAS}

Ignacio J. López Hernández

Alejandro O'Reilly y el ingeniero Beltrán Beaumont en Santiago de Cuba: causas y principios de un proyecto de fortificación frustrado (1764-1766).

\section{ISSN 1988-7868}

de la ciudad a Guantánamo, bahía con una capacidad defensiva mucho mayor y con aguas y terrenos más apropiados para fondear y hacer aguadas, establecer plantaciones agrícolas e incluso explotar sus valiosas salinas. ${ }^{69}$

Ninguna de estas últimas recomendaciones fue finalmente atendida, siendo tan solo evaluado su proyecto para la reconstrucción del castillo de San Pedro de la Roca. A este último, el célebre ingeniero Juan Martín Cermeño añadiría diferentes enmiendas con las que se constituyó el proyecto final aprobado por el rey. ${ }^{70}$ Por tanto, este último acabó desbancando al plan de defensa y fortificación de la bahía formado por Beltrán Beaumont y Alejandro O'Reilly. Ambos tuvieron noticias del cambio de proyecto cuando se encontraban en espera de destino en la península. Fue el secretario de estado Arriaga quien, como deferencia a su comisión en Santiago, envió a O'Reilly los informes y proyectos para su evaluación. El mariscal fue condescendiente con el proyecto de Cermeño, si bien no renunció a que en un futuro se pudiera completar con la construcción de pequeños fuertes en la Socapa y la Estrella. ${ }^{71}$ Por su parte, los hermanos Beaumont no se mostraron tan convencidos por el nuevo proyecto. A pesar de la notoria diferencia de escalafón, estos criticaron, sin ambages y con cierta osadía, que se hicieran proyectos desde la península sin el conveniente conocimiento del terreno, lo que faltaba a una de las máximas del arte de la fortificación:

$Y$ aunque veneran con el mayor respecto las disposiciones de su comandante [Cermeño] no pueden menos de hacer presente a S.M. por el conocimiento que

\footnotetext{
${ }^{69}$ Sobre estas mismas consideraciones se manifestaron en décadas anteriores ingenieros, gobernadores y oficiales de la Armada, si bien el despliegue de medios necesario acabó disuadiendo cualquier tentativa. Véase Francisco Cagigal de la Vega a José del Campillo y Cossío, Santiago de Cuba, 6 de abril de 1742, AGI, Santo Domingo, 2106. También son conocidas las aspiraciones británicas sobre la que llamaron Cumberland Harbour, llegando incluso a establecer una colonia provisional con anterioridad a la llegada de Vernon en julio de 1741. Pedro Luengo Gutiérrez, "The British settlement in Guantánamo (Cuba). Urban and defensive features", en A Fortified Sea: The Defence of the Caribbean During the Eighteenth Century and its Precedents (Congreso internacional, Sevilla, 26 de septiembre de 2018).

${ }^{70}$ López Hernández, "Crame, Cermeño...", op. cit.; Juan Carrillo de Albornoz y Galbeño, "La edad de oro de la fortificación abaluartada en España y ultramar", Revista de historia militar, $\mathrm{n}^{\circ}$ extraordinario (Madrid, 2012), p. 86; Para conocer la labor supervisora de Cermeño en las fortificaciones de este periodo en Ultramar se recomienda la lectura de Pedro Luengo, Manila, Plaza Fuerte (1762-1788). Ingenieros Militares entre Asia, Mérica y Europa. Madrid: CSIC, Ministerio de Defensa, 2013, pp. 79-109.

71 "Despues de perfeccionadas estas obras sera facil con una pequeña dotacion hacer en la altura de la socapa y en la de la estrella dos pequeños fuertes o torres de poco costo, que dilataran mucho las operaciones del enemigo". O'Reilly a Arriaga, Madrid, 23 de septiembre de 1767, AGI, Cuba, 1113.
} 


\section{AMERICANISTAS}

Ignacio J. López Hernández

Alejandro O'Reilly y el ingeniero Beltrán Beaumont en Santiago de Cuba: causas y principios de un proyecto de fortificación frustrado (1764-1766).

\section{ISSN 1988-7868}

tienen [...] que semejantes correcciones se hacen sobre el terreno y no a 1700 leguas. ${ }^{72}$

Como es de esperar, la opinión de ambos ingenieros fue ignorada. Tampoco prosperó nunca la idea de O'Reilly de reducir su proyecto a las dos fortificaciones en la Socapa y la Estrella. Según recogen diversos autores, las obras siguieron su curso bajo el proyecto de Cermeño, ${ }^{73}$ si bien se ha podido precisar que el resultado final fue consecuencia del diseño de Crame ${ }^{74}$. Lo cierto es que, una vez concluida la reconstrucción del castillo, aún siguió siendo necesario un plan de defensa más complejo, de lo que son testimonio los planos de Ventura Buceta con los que presumiblemente trató de promover de nuevo el proyecto de 1764 .

\section{Conclusiones}

El análisis del plan defensivo de O'Reilly y Beaumont en Santiago de Cuba proyecta diferentes conclusiones, que emanan tanto de su fracaso como de sus propias implicaciones técnicas y estratégicas. Primeramente, es posible advertir cómo los límites de competencias sobre la fortificación de la isla no estaban plenamente definidos. De ello sería consecuencia el conflicto entre el ingeniero director Silvestre Abarca y O'Reilly. En opinión del mariscal, los plenos poderes otorgados por el rey para la reorganización militar de la isla se extendían igualmente al ámbito de la fortificación, algo a lo que se negaba Abarca. Sobre esto mismo, los hermanos Beaumont relatan cómo "ofrecieronse varios debates el Exmo Conde de Ricla y el Exmo Dn Alexandro OReily con el Director en asumpto de fortificaciones". ${ }^{75}$ La resistencia que presentó Abarca a su subordinación

\footnotetext{
72 Descargos de los dos ingenieros..., Pedro y Beltrán Beaumont, Madrid, 11 de septiembre de 1767, AGI, Santo Domingo, 2121.

${ }^{73}$ Así lo aseveran autores como Carrillo de Albornoz y Galbeño, op. cit., p. 86; Juan Carrillo de Albornoz y Galbeño, "Los Ingenieros militares Juan y Pedro Cermeño", en Antonio de Lizaur y de Utrilla (ed.), $L a$ Ilustración en Cataluña: La obra de los Ingenieros Militares. Barcelona: Ministerio de Defensa, 2013, pp. 179-181; Zaldívar Morales, op. cit. p. 221; López Rodríguez, op. cit., p. 13. Las obras serían aprobadas según un nuevo plan de obras formado por el gobernador Esteban de Olóriz bajo la dirección del ingeniero Francisco Suárez Calderín. Véase Pedro Cruz Freire, "El gobernador Esteban de Olóriz y el proyecto de reforma para el Castillo del Morro de Santiago de Cuba (1767-1771)", Revista de la CECEL, $\mathrm{n}^{\circ}$ 13, (Madrid, 2013), pp. 139-150.

${ }^{74}$ López Hernández, "Crame, Cermeño...", op. cit.

${ }^{75}$ Descargos de los dos ingenieros..., Pedro y Beltrán Beaumont, Madrid, 11 de septiembre de 1767, AGI, Santo Domingo, 2121.
} 


\section{AMERICANISTAS}

Ignacio J. López Hernández

Alejandro O'Reilly y el ingeniero Beltrán Beaumont en Santiago de Cuba: causas y principios de un proyecto de fortificación frustrado (1764-1766).

\section{ISSN 1988-7868}

venía elevada por su indiscutible autoridad. O'Reilly, por su parte, consideraba las atribuciones del ingeniero en un ámbito meramente técnico. En este sentido, y no sin cierta ironía, O'Reilly declararía que "según este principio era menester escoger los jefes de escuadra y comandantes de fuerzas navales entre los constructores de navíos". ${ }^{76}$

No obstante, el mariscal fue hábil al atribuirse funciones sobre la fortificación de la isla durante la expedición que efectuó para organizar las milicias de Cuba, para lo que fue fundamental la figura de Beltrán Beaumont. Así, aprovechando el bajo rango del ingeniero, ${ }^{77}$ O'Reilly lo separó de la debida subordinación a su director del arma, utilizando sus conocimientos técnicos sobre fortificación, geometría y dibujo para formular sus propios proyectos. En realidad, esta relación entre técnico y hombre de armas resultó hasta cierto punto habitual desde el siglo XVI, de lo que fue uno de los primeros casos americanos la comisión conjunta en La Habana del ingeniero Bautista Antonelli y el gobernador Juan de Tejeda. ${ }^{78}$

Por su parte, la protección de O'Reilly y Ricla proveía a Beltrán Beaumont de ciertas responsabilidades que sobrepasaban las de su escalafón. De esta forma, los hermanos Beaumont se aseguraban un rápido ascenso, si bien ellos mismos fueron conscientes de la caducidad de aquella situación evitando en un principio hacerse cargo de los trabajos en Santiago. Sus temores eran fundados, tal y como se comprobó después de la marcha de O'Reilly y el conde de Ricla. Año y medio después los ingenieros serían

\footnotetext{
76 Torres Ramírez, Alejandro O'Reilly en las Indias..., p. 48.

77 El grado de ingeniero extraordinario con que contaba Beltrán Beaumont tenía una equivalencia de teniente de infantería. Horacio Capel, Joan-Eugeni Sánchez y Omar Moncada, De Palas a Minerva: la formación científica y la estructura institucional de los ingenieros militares en el siglo XVIII. Madrid: CSIC, 1988, p. 257.

${ }^{78}$ Alicia Cámara Muñoz, Fortificación y ciudad en los reinos de Felipe II. Madrid: NEREA, 1998, p. 69. Un estudio reciente que aborda la relación entre ingenieros y gobernantes se debe a la coordinación de Alicia Cámara Muñoz y Margarita Ana Vázquez Manassero (Eds.), Ser hechura de: Ingeniería, fidelidades y redes de poder en los siglos XVI y XVII. Madrid: Fundación Juanelo Turriano, 2019. Véase también Ignacio J. López Hernández, "Ingenieros militares, gobernadores y procesos constructivos en Santiago de Cuba en el siglo XVIII", en Yolanda Guasch Marí, Rafael López Guzmán e Iván Panduro Sáez (eds.). Identidades y redes culturales. V Congreso Internacional de Barroco Iberoamericano. Granada: Editorial Universidad de Granada, 2021.
} 


\section{AMERICANISTAS}

Ignacio J. López Hernández

Alejandro O'Reilly y el ingeniero Beltrán Beaumont en Santiago de Cuba: causas y principios de un proyecto de fortificación frustrado (1764-1766).

\section{ISSN 1988-7868}

relevados y enviados de vuelta a España, lo que no tendría repercusiones para sus futuros ascensos. ${ }^{79}$

A pesar de todo, el fracaso del proyecto no se debió en exclusiva a intrigas personales. Por un lado, el factor económico pesó tanto como la oposición del gobernador Cagigal, pues apenas nada llegó a Santiago de los 500.000 pesos librados para la fortificación de la isla. ${ }^{80}$ Sin embargo, los motivos más determinantes fueron de carácter técnico y estratégico, según se desprendió del informe de Crame. Para el ingeniero, el reconocimiento del entorno del que partía el proyecto era erróneo, algo que puede certificarse con la comparación de uno de los mapas documentados con la cartografía actual. ${ }^{81}$ Esto, si bien determinaba algunas modificaciones en los proyectos en los montes de la Socapa y la Estrella, no salvaba los problemas por el frente de campaña del Morro. En este punto, se llega a percibir cómo el informe y proyecto de Crame tendía más a recomponer la obra previa y desacreditar el plan anterior que en proponer una intervención real para la defensa de la plaza. Esto mismo concuerda con su consideración final acerca de abandonar la ciudad y volar sus fortificaciones. Esta medida drástica respondía sin embargo a consideraciones geoestratégicas muy sopesadas que se integraban en una nueva forma de concebir la defensa del Caribe que Zapatero llamó "defensa por indefensión". ${ }^{82}$ Así, Crame buscaba concentrar esfuerzos en puertos fundamentales de cara a reducir potenciales objetivos para el enemigo y desplegar amplios dispositivos allí donde la integridad política de la isla residía. Solo de esta manera se entiende cómo se acabó privilegiando la defensa de La Habana frente a otros puntos

\footnotetext{
${ }^{79}$ Beltrán y Pedro Beaumont a Arriaga, Madrid, 20 de agosto de 1767, AGI, Santo Domingo, 2121. La solicitud para su promoción a ingenieros ordinarios fue cursada por el secretario de guerra Juan Gregorio Muniáin. Aunque no se ha localizado el expediente de la concesión, consta como en años posteriores en sus diferentes comisiones -Beltrán en Navarra y Pedro en Cataluña- ya constaban como ingenieros ordinarios. Véase Mercurio historico y politico. Madrid: Imprenta Real, Tomo II, p. 269; Horacio Capel et al., Los ingenieros Militares en España. Siglo XVIII. Repertorio biográfico e inventario de su labor científica y espacial. Barcelona: Universitat de Barcelona, 1983, p. 64.

${ }^{80}$ Cagigal a Bucareli, Santiago de Cuba, 7 de mayo de 1766, AGI, Cuba, 1051, Carta 9.

${ }^{81}$ Plano del Castillo del Morro en la Isla Cuba ..., CGE, Cartoteca, Ar.j-t.10-c.2-296.

${ }^{82}$ Esta tenía lugar cuando se desocupaban y demolían fortificaciones en aquellos lugares donde no hubiera recursos para la defensa o no interesara estratégicamente, a fin de evitar que el enemigo ocupara sus defensas y se hiciera fuerte en ellas. Véase Zapatero, Historia del Castillo..., p. 145; Zapatero, La Guerra del Caribe..., 1990, pp. 97-120. Un episodio conocido fue el de la destrucción del castillo de Araya en 1762. Graziano Gasparini, Los Antonelli: arquitectos militares italianos al servicio de la Corona española en España, África y América, 1559-1649. Caracas: Editorial Arte, 2007, p. 103.
} 

causas y principios de un proyecto de fortificación frustrado (1764-1766).

\section{ISSN 1988-7868}

de la isla que prácticamente permanecieron inmutables en años sucesivos. Ello marca un rasgo diferenciado de la fortificación española en el Caribe, lo que se aprecia más claramente si se compara el centralismo defensivo cubano con el policentrismo francés en la vecina isla de Santo Domingo. ${ }^{83}$

\footnotetext{
${ }^{83}$ Pedro Luengo e Ignacio J. López Hernández, "Fortificaciones francesas en el Caribe frente a los ataques de la Guerra de los Siete Años", Aldaba, no 43 (Melilla, 2018), pp. 275-278; Esta estrategia se remontaría a los primeros años de la Saint-Domingue francesa. Véase Ignacio J. López Hernández, "Fundar para defender: fortificación y geoestrategia en Saint-Domingue entre 1665 y 1748", Gladius, Vol. 39 (Madrid, 2019), pp. 147-168; Ignacio J. López Hernández, "La ciudad amurallada en Saint-Domingue: proyectos de fortificación entre el ideal y lo pragmático", Studi e ricerche di storia dell'architettura, no 7 (Palermo, 2020), pp. 94-105.
} 